\title{
ICT Transfer Business Model Development
}

\author{
Viktorija Stepanova and Ingars Erins
}

\begin{abstract}
Technology transfer plays a significant role in the development of any country, specifically in our age of rapidly developing technologies that have a major impact on business processes and the overall quality of life. Software development and information technology (IT) service segments are the main drives promoting the growth of the information and communications technology (ICT) market, which allows enterprises to save such valuable resources as time and money. Development of new technologies is closely connected with selection and assessment of ideas, decision making and marketing activities. Technology transfer involves the knowledge about development methods, strategy selection, production samples, quality assessment and commercialization processes, technology life cycles and technology availability to a wide range of end users. The aim of the research is to develop an ICT transfer model for practical application by software developers and project managers, uniting numerous information technology standards with innovation commercialization processes. The authors use independent component analysis and synthesis method that unite model elements and connections into one integrated system.
\end{abstract}

Index Terms-Process assessment, process-orientation, six sigma, software quality management, software engineering.

\section{INTRODUCTION}

We deal with information and communications technologies on a daily basis and their range is constantly growing. Information and communications technology (ICT) is the body of knowledge, methods, procedures and technical equipment, which ensures acquisition, storage and dissemination of any information using computers and telecommunications tools [1]. Automation of manual functions allows saving time and money; thus, it is rapidly becoming an integral part of everyday life, which is attested by statistical data:

- Almost all (92\%) small and medium-sized enterprises in Europe use computers and the Internet [2];

- The demand for ICT specialists is growing each year [3];

- ICT revenues are growing in Europe. In 2018, ICT sector revenues reached 686 billion EUR $(+0.7 \%$ compared to 2015) [4];

- In EUROPE, the value of the overall software market in 2009 was 229 billion EUR, and it grew by $1.5 \%$ on average each year. It is forecast that the average annual growth from 2015 to 2020 will accelerate to $2.9 \%$ and in 2020 will reach almost 290 billion EUR [5].

Manuscript received May 12, 2019; revised December 28, 2019

Viktorija Stepanova and Ingars Erins are with the Department of Computer Science and Information Technology, Riga Technical University, Riga, Latvia (e-mail: viktorija.stepanova@rtu.lv).
However, new opportunities come along with a range of problems that should be addressed in connection with the global ICT ecosystem. Development of new technologies is closely related with repeated decision making: strategy selection, selection of production methods and the choice of the quality assurance system. Technology development process is influenced by such factors as project budget, time, interaction among participants and cooperation networks that provide a safe communications channel for information exchange and faster access to new knowledge. Technology transfer can be seen as the process of information transmission from the supplier to the consumer. Normally, this process envisions several stages and involves at least two individuals or functional units that transmit information, knowledge, technology, or experience from one to another. Technology transfer involves knowledge about development methods, production standards, quality assurance, launch and distribution processes to ensure technology development and availability to a wide range of end users.

Large and medium-sized enterprises that are focused on software development and IT services have their own strategies for product development and life cycle. They normally have a large customer base, large number of projects and sufficient financing for technology development and process management. Smaller enterprises or research institutions usually do not have similar resources. At the same time, for example, many software projects are developed on the university premises, and they are not used and/or they are kept in the form of prototypes, reports and publications. In their majority, universities do not have their own customer base, no motivation and no technology transfer model to launch a product on the market. Many projects are financed from the European Commission funds and as soon as the maintenance financing runs out, many ICT solutions remain unused and are kept on the research institution premises not generating any profit for software developers or the research institution. There are also many software development projects at some time implemented by researchers and students, but their aim has not been connected with product marketing but rather with conducting experiments, testing and publishing of experiment results.

The present paper describes the ICT transfer model developed by the authors based on the best world practices in software development. The developed business model comprises IT standards and project management concepts; it describes and visualizes the main steps from software development to gaining real profit

\section{RELATED WORK}

The number of research projects related to knowledge and technology transfer is annually growing on the global scale. Bibliometric analysis proved topicality of the issue $-\mathrm{WoS}$ and SCOPUS databases alone annually publish about 1,700 papers related to this research field [6]. It is important to note that a majority of papers on the issue are published by researchers from China, the USA and Germany. Considering technology transfer models it may be concluded that so far there is no 
unified model used by technology developers to transfer knowledge to technology users. The authors use different approaches and their experience under the influence of different factors varies greatly.

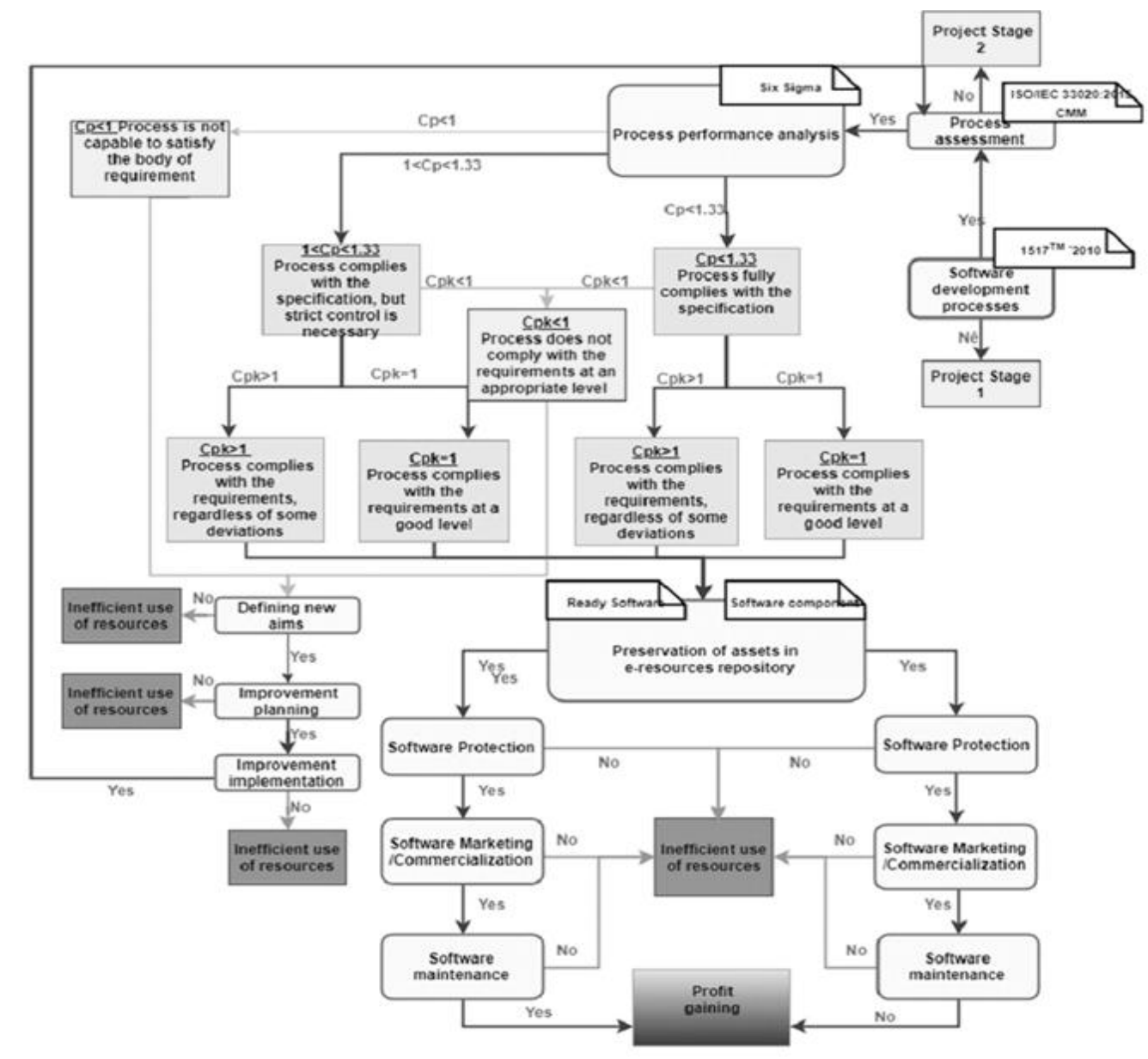

Fig. 1. ICT transfer model.

Qingwen Sun from Beijing National Technology Transfer Center in cooperation with Hua Feng from China Research Center for Industrial Economic Security in their 2016 research suggest a new approach to ensuring interrelation among scientific research institutions, municipalities and enterprises focusing on local economic development. In their work, the authors summarize the data on cooperation models and describe CAS Innovation Park, which has become a bridge between the scientists and entrepreneurs and at present drives development of local economies [7]. In 2016, researchers from India also published their work focusing on communication issues, access to information and its impact on technology transfer. In their paper, the authors suggested STAR (communications) model for technology transfer and analyzed application opportunities of ICT based communications systems for faster and more efficient technology transfer [8]. Concerning the models developed in the field of software engineering, the 2015 paper published in IEEE "An Exploratory Study on Technology Transfer in Software Engineering" should be mentioned. The authors characterized technology transfer processes within software engineering research projects involving both academic and industry partners. In the paper, the authors conducted a research survey in cooperation with industry and academic partners, summarized the existing theories and selected relevant hypotheses [9].

ICT development and market launch are closely connected with knowledge management that is the core element of knowledge creation, accumulation, analysis and application. The authors of the current research suggest while developing software to pay more attention to re-usable assets with an aim to create added value for software or its components. Based on information technology standard 1517TM - 2010 [10], information technology process assessment standard ISO/IEC 33020:2015 [11], Capability Maturity Model (CMM), technology transfer manuals [12] and their synthesis, a new model has been developed that integrates numerous information technology standards with innovation commercialization processes. As a result, it will provide opportunity to design high quality ICT solutions that fully comply with specifications, create added value to their components and promote user understanding about technology launch and distribution processes. Therefore, performance indicators of an enterprise or research institution will improve in its turn facilitating the processes related to technology market launch.

\section{MATERIALS AND Methods Related WorK}

The following methods have been used in the ICT transfer model design:

- Analysis of research literature with an aim to evaluate the appropriate methodologies for model design [6];

- Information processing method for processing of the acquired data and ranging of the results;

- Process-oriented method for knowledge management within projects [13];

- IEEE information technology standard 1517TM - 2010 [10] defining software development process; 
- Information technology process assessment standard ISO/IEC 33020:2015 [11] and the current integrated CMMI methodology [12] for process assessment;

- Six Sigma statistical method [14] for the analysis of process performance of the existing software projects;

- Causal Decision tree structure [15] and computer visualization [16] for modeling.

In the present research, the authors use independent component analysis and synthesis method that unite model elements and connections into one integrated system.

\section{ICT TRANSFER MODEL}

Many enterprises and research institutions often conduct their activities as projects. The project has a definite starting point and a desired outcome, as well as the necessary assets (resources) and project management procedures. It is important to implement a project to meet the highest standards and to realize timely when the resources are used inefficiently and the project fails to generate profit.

TABLE I: ICT TRANSFER MODEL'S INTERIM RESULTS

\section{Interim result \\ Project at the first stage of development}

Project at the second stage of development

Process is not capable to meet the body of requirements

\section{Process meets the requirements at a good level}

Process complies with specifications, but strict control is necessary

Project fully complies with specifications

Project meets the requirements, regardless of some deviations

Project meets the requirements at a good level

\section{Recommendation \\ To continue operations, it is necessary to clearly define and document software development processes based on software product development employing re-usable assets}

To continue operations, it is necessary to analyze process performance using software development process performance self-assessment system

It is necessary to set new goals and objectives. Process improvement should be planned and coordinated with the organization's vision; it is also necessary to improve definite processes to reach the goal

Software or its components with the accompanying documents may be stored in the e-resource repository as an organization's asset

Software or its components with the accompanying documents may be stored in the e-resource repository as an organization's asset

Software or its components with the accompanying documents may be stored in the e-resource repository as an organization's asset

Software or its components with the accompanying documents may be stored in the e-resource repository as an organization's asset

Software or its components with the accompanying documents may be stored in the e-resource repository as an organization's asset

Uniting knowledge management process oriented approach [10], information technology standard 1517TM 2010, information technology process assessment standard ISO/IEC 33020:2015, Capability Maturity Model and technology transfer manuals, the authors suggest an information and communications technology transfer model, which allows using technology transfer and commercialization to manage ICT solutions from the process perspective, analyzing a process stage and providing recommendations for sustainable development and improvement of that stage.

The model has been visualized on the open platform Draw.io [15]; it provides only limited information on software project processes that any decision maker or project implementer may understand. The developed model (see Fig. 1) allows identifying software development projects that fully meet specifications and are capable of generating additional benefit and potential profit for an organization.

ICT transfer model envisages the following potential outcomes represented as rectangles:

- Positive outcome and project aim "Profit gaining" that is one of the most important performance indicators of an organization, which promotes motivation to develop technology;

- Negative outcome "Inefficient use of resources" characterized by small added value, which means that there is no use to continue and develop the project;

- Interim results that ensure initial control and allow determining the stage of project development and make relevant decisions to implement and improve the processes (see Table I).

Monitoring ICT transfer process flow it is possible to define the range of tasks to be performed to reach a definite result or timely make decision on project development.

Within the developed model, software design, launch and commercialization processes are divided into numerous continuous stages. Graphically, the processes are represented as rectangles with round corners, the arrows indicate process sequence and rectangles show the outcomes and interim results.

With regard to the fact that programmers tend to spend the main part of their time writing codes, developing design or drawing up documents that are very similar to the already existing ones, software design starts with software development processes based on software product development with re-usable assets (IEEE information technology standard $1517^{\mathrm{TM}}$ - 2010). Software design, specification, source code, documentation, test sets, manual procedures, etc. developed for application in various contexts can be utilized as re-usable assets. For each software development process, certain activities to be completed are defined to develop and maintain the software or software elements to gain additional benefit from the re-use of the existing software component. Software design processes and activities are described in more detail in one of the previous papers by the authors [17]. The processes with the main outcomes are presented below:

1) Software launch $\rightarrow$ Software with re-usable components (modules) + documentation.

2) Software requirement analysis $\rightarrow$ Software requirements + documentation + assessment.

3) Software architecture design $\rightarrow$ Software architecture with re-usable components + documentation + assessment.

4) Detailed software design $\rightarrow$ Detailed design of each software asset + documentation.

5) Software structure $\rightarrow$ Testing of software components for re-usability.

6) Software integration $\rightarrow$ Software integration plan + 
forms to be re-used + documentation.

7) Software qualification test $\rightarrow$ Software qualification test results + documentation.

When all these preconditions are met, it is necessary to assess project quality and development stage. For this purpose, it is envisaged to use a software performance self-assessment system developed by the authors; the system is based on information technology process assessment standard ISO/IEC 33020:2015. This standard allows promoting software quality self-assessment to improve and define process quality, as well as to build software profile with process levels. Five process performance levels (PPL) have been defined for process assessment; the authors set values from 0 to 1 for quantifiable metrics for each stage (see Table II).

TABLE II: ASSESSMENT SYSTEM OF SOFTWARE DEVElopment PROCESS PERFORMANCE ICT TRANSFER MODEL'S INTERIM RESULTS

\begin{tabular}{|c|c|c|}
\hline PPL & Value & Description \\
\hline 0 & 0 & Process is not defined \\
\hline 1 & 0.1 & Process is defined \\
\hline \multirow[t]{2}{*}{2} & 0.2 & $\begin{array}{l}\text { Process is defined and documented, but the } \\
\text { action is not yet started }\end{array}$ \\
\hline & 0.3 & Process is started \\
\hline \multirow[t]{2}{*}{3} & 0.4 & Process is implemented \\
\hline & 0.5 & $\begin{array}{l}\text { Process is implemented and the results are } \\
\text { documented }\end{array}$ \\
\hline \multirow[t]{2}{*}{4} & 0.6 & Process is assessed \\
\hline & 0.7 & Process is assessed and results are documented \\
\hline \multirow[t]{3}{*}{5} & 0.8 & Process optimization requirements are defined \\
\hline & 0.9 & Process is optimized \\
\hline & 1 & Process is optimized and documented \\
\hline
\end{tabular}

Thus, obtaining a definite project profile (Fig. 2) certain questions emerge: "To what extent does the project meet customer requirements?", "Is strict control needed?", "Should the process be optimized?" Six Sigma methodology may help project managers obtain answers to these questions.

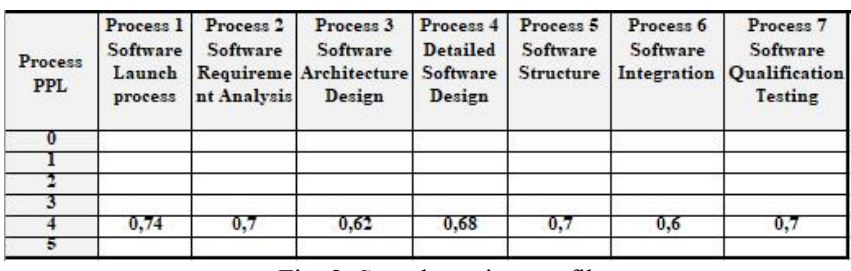

Fig. 2. Sample project profile.

In order to use this methodology efficiently, it is necessary to understand the following indicators:

- Use either SI (MKS) or CGS as primary units. (SI units are encouraged.) English units may be used as secondary units (in parentheses). An exception would be the use of English units as identifiers in trade, such as "3.5-inch disk drive".

- Specification that defines product requirements to ensure it is usable. Specifications normally set nominal control limits (USL - upper specification limit, LSL - lower specification limit) and exceeding these limits is seen as a perverse process outcome (see Fig. 3);

- Mean process value $(\mu)$. The further process value is from the mean value and the closer it is to the control limit, the smaller is the number of defects;

- Standard deviation ( $\sigma$ sigma) demonstrates to what extent the process deviates from the mean process value. Normally, standard deviation is set for a process that is subject to statistical control, and that can be influenced only by process changes that influence process variability. The smaller is sigma, the more stable and beneficial is the outcome.

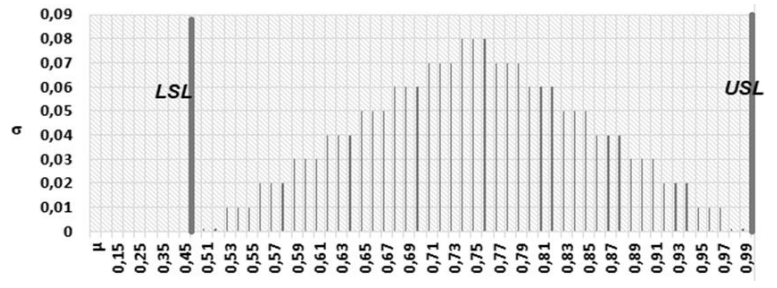

Fig. 3. Projects specification margin.

As a result of application of Six Sigma methodology, two process quality indicators can be obtained - Cpk and Cp. These indicators are widely used in statistical process management and they facilitate controlled process management. $\mathrm{Cp}$ index indicates the potential process capabilities and shows how many times six sigma may be accommodated within the range.

$\mathrm{Cp}$ index is calculated using specification limits and only standard deviation. In turn, Cpk index is used to assess how far the mean process value is from the specification. The higher is $\mathrm{Cpk}$ value, the better the process meets the requirements.

Normally, transferring the usable software to the customer, it is necessary to ensure that the lowest process value (LSL) at the moment of transfer is 0.5 , with the maximal value reaching 1 (USL), when all design processes have been completed, optimized and documented. A project manager may set control specification limits separately for each project taking into consideration the needs of each particular customer or the aims of an organization.

For example, the project represented in Fig. 2 has the mean process value $(\mu)$ of 0.676 , but standard deviation ( $\sigma$ sigma) is 0.049 (Excel formulas have been used in calculations). For this project, $\mathrm{Cp}=1.701$ and $\mathrm{Cpk}=1.197$ (indices have been calculated using an online calculator [18] or found in the table drawn up in this paper for software development projects (see Fig. 4).

TABLE III: INTERPRETING THE PROCESS CAPABILITY INDEX

\begin{tabular}{ll}
\hline \hline Result & Interpretation \\
\hline $1.33<\mathrm{Cp}$ & $\begin{array}{l}\text { The process fully complies with specifications } \\
\text { The process complies with specifications, but } \\
\text { strict control is necessary } \\
\text { The process is not capable to meet the body of } \\
\text { requirements } \\
\text { The process meets the requirements at a good } \\
\text { level }\end{array}$ \\
$\mathrm{Cpk}=1.00$ & $\begin{array}{l}\text { The process meets the requirements, regardless of } \\
\text { some deviations } \\
\text { Quite likely, the process does not comply with the } \\
\text { requirements at an appropriate level }\end{array}$ \\
\hline \hline
\end{tabular}

The interim results can be obtained considering the calculated indices and conclusions regarding whether the project is being successfully implemented to reach the planed outcomes can be made (see Table III calculated based on Chandrakant K. Karale' research [19]). In case the project does not comply with the requirements at an appropriate level based on the process-oriented method, it is necessary to plan improvements of each project process and, respectively, to improve the specified processes until the aim is reached.

In our case, it is desirable to get an interim result in the form of a software project where re-usability requirements are set for each software component; each component has a detailed design including a test for re-usability and an integration plan. It is also important to ensure that all processes are documented, assessed and optimized. Thus, a 
decision maker may make an informed conclusion whether the project complies with the requirements set in numerous standards and whether it is capable to generate profit for its developers.

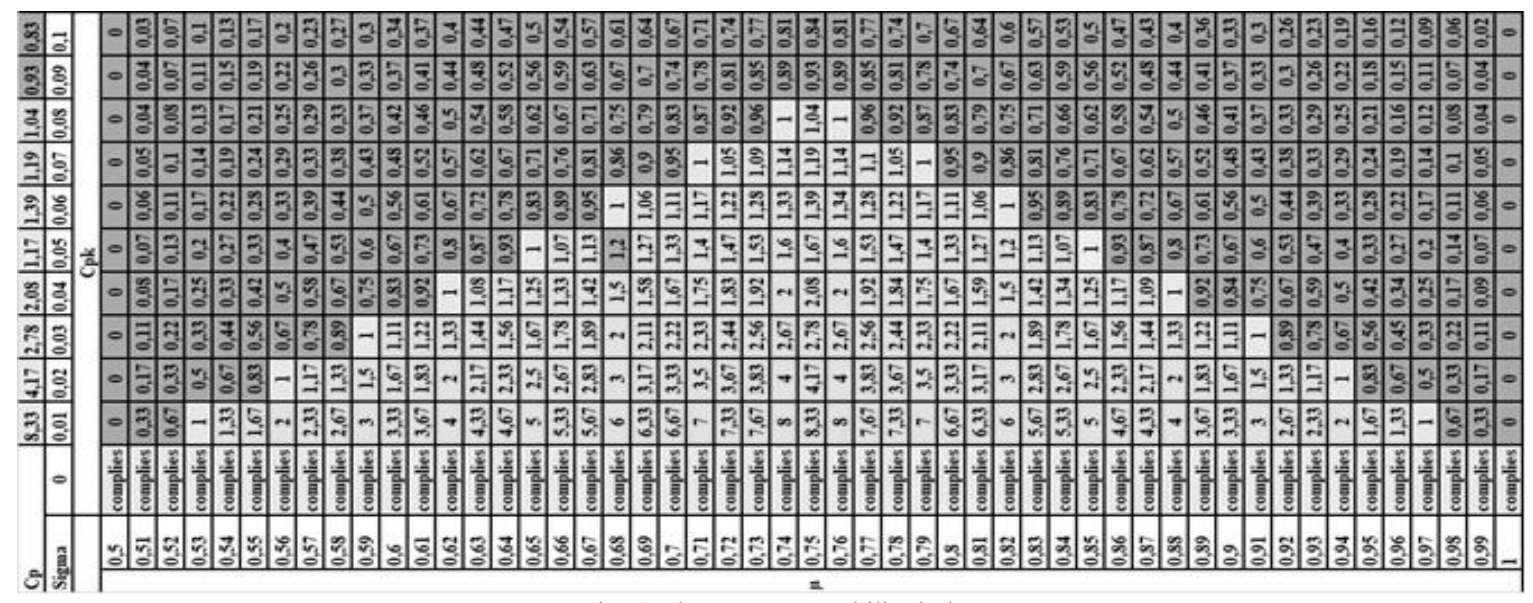

Fig. 4. The process capability index.

TABLE IV: PROS AND CONS OF THE ICT TRANSFER MODEL

\begin{tabular}{lc}
\hline \hline Benefits & Drawbacks \\
\hline$\checkmark$ Suitable for different software projects with various requirements & $\checkmark$ Dependence on group achievements \\
$\checkmark$ This model can be used in process management within any ICT project & $\checkmark$ Processes should be monitored at each \\
$\checkmark$ Pays particular attention to drawing up precise documentation & $\checkmark$ Preliminary knowledge about numerous \\
$\checkmark$ Low estimated costs & standards and practices is needed \\
$\checkmark$ In a short period creates valuable information volume & $\checkmark$ Complicated process management \\
$\checkmark$ As it is based on numerous best software development practices, any developer can use the model and & $\checkmark$ Large volume of documents \\
$\quad$ manage a project & $\checkmark$ Lack of process automation tool \\
$\checkmark$ Includes software development standards & \\
$\checkmark$ Monitors and develops the projects with good potential & \\
$\checkmark$ Develops rational plans and graphs & \\
$\checkmark$ Can be used within small budget projects & \\
$\checkmark$ Suitable for small organizations & \\
$\checkmark$ Added value from the re-use of the asset & \\
$\checkmark$ Ability to provide recommendations for sustainable development and improvement of a stage &
\end{tabular}

Further, this project can be regarded an organization's asset that is stored in an organization's e-resource repository and that can be used in a variety of ways:

- Software with the accompanying documents can be transferred to the customer (in case the project has been commissioned by this customer);

- Software can be used for the needs of the organization itself;

- Certain software components can be re-used developing new projects;

- Software or separate software components can be sold to the interested enterprises.

At this stage, it is worth considering software market launch.

Software protection process:

1) Software or its component protection solutions should be selected;

2) Protection opportunities should be evaluated;

3) The most appropriate software protection solution should be selected;

Software marketing and commercialization process:

4) A potential user of software or its component should be determined;

5) The enterprises that might be interested in commercializing definite software should be determined;

6) Market survey should be conducted;

7) The existing business relations should be identified;

8) Sources of financing should be evaluated;
9) The optimal commercialization strategy should be selected;

Software maintenance process

It is necessary to appoint a person or a group of persons who are competent in the given software and who will provide the necessary support and help in using it.

Meeting all requirements, the assets owned by the organization can be converted into cash. The results have a direct impact on the performance indicators of an enterprise or a research institution. The developed ICT technology transfer model is based on the best practices, and it includes:

- software development standards;

- quality assessment;

- planning;

- decision making.

The model ensures compliance to many requirements in introducing ICT solutions to the market and development in the contemporary dynamic digital environment.

\section{Pros AND CONS OF THE ICT TRANSFER MODEL}

Despite the obvious benefits the practical application of the model may provide, model drawbacks should also be considered. Summary of benefits and drawbacks will help in making an informed decision on further development of the model. The results are defined and summarized in Table IV.

The main benefits to be highlighted are that larger budget is not necessary to launch the model; it can be used by any software developer in different projects with various requirements. The model included numerous standards that 
increase product quality and allow selecting the projects to gain additional benefit. The model envisions opportunity to provide recommendations and plan activities for development and improvement of the existing project.

Reflecting on the drawbacks, it can be noted that processes should be monitored at each stage and that involves dealing with a large number of documents, which requires preliminary knowledge about numerous standards, methodologies and marketing activities.

The next stage involves development of a prototype of a software tool for ICT transfer model automation, which will allow facilitating process management and application without specific preliminary user knowledge about standards and methodologies. At each stage, a software tool will provide recommendations for further technology development and a link to the related documents or methodology.

\section{CONCLUSION}

Within this paper, an ICT transfer model that joins numerous information technology standards with innovation commercialization processes has been developed. The model is based on process-oriented approach that allows by means of technology transfer and commercialization to manage ICT solutions from process perspective, to analyze process stage and provide recommendations for sustainable software development and improvement. The paper provides description of a software quality assessment system and results of process performance analysis, which the authors propose using to check whether system processes comply with specifications. This model will facilitate the processes related to technology market launch and will add value to the existing assets of an enterprise or research institution.

Within the framework of the paper, benefits and drawbacks of the model have been identified and directions for further development have been defined.

\section{CONFLICT OF INTEREST}

The authors declare no conflict of interest.

\section{AUTHOR CONTRIBUTIONS}

Viktorija Stepanova concuted and designed the study. She wrote the manuscript with support from Ingars Erinš. Both authors discussed the results and contributed to the final manuscript. Ingars Erinš had approved the final version.

\section{REFERENCES}

[1] University of Latvia, "Information technology keywords," Project Improvement of Competence of General Education Teachers Involved in Vocational Education, Riga, vol. 1, 2013.

[2] Digital economy and society statistics - Enterprises. [Online]. Available:

http://ec.europa.eu/eurostat/statistics-explained/index.php/Digital_eco nomy_and_society_statistics_-_enterprises

[3] Eurostat. Employed ICT specialists - Total. [Online]. Available: http://appsso.eurostat.ec.europa.eu/nui/show.do?dataset=isoc sks itsp t\&lang=en

[4] Slowing Growth of the European ICT Market. [Online]. Available: https://www.eito.com/press/Press-Releases-2016/Slowing-Growth-ofthe-European-ICT-Market

[5] European Commission, The economic and social impact of software \& services on competitiveness and innovation (SMART 2015/0015), Final Study Report, EU, 2017.

[6] V. Ponomarenko and I. Novickis, "A review of information technology transfer process, its topicality, and related models," Rezekne Academy of Technologies, 2017.
[7] O. Sun and H. Feng, "Innovating the new model of academy locality cooperation," in Proc. 2016 International Conference on Industrial Economics System and Industrial Security Engineering (IEIS) Proceedings, IEEE, 2016.

[8] A. K. Saini and V. K. Khurana, "ICT based communication systems as enabler for technology transfer," in Proc. 2016 3rd International Conference on Computing for Sustainable Global Development, 2016, pp. 90-99.

[9] P. D. Vetro and A. D. M. Fernandez, "An exploratory study on technology transfer in software engineering," in Proc. 2015 ACM/IEEE International Symposium on Empirical Software Engineering and Measurement (ESEM) Proceedings, IEEE, 2015, pp. 86-95.

[10] 1517-2010 System and software life cycle processes. Reuse processes, IEEE Standard for Information Technology, USA: IEEE, 2010

[11] Information technology. Process assessment, process measurement framework for assessment of process capability, Standard ISO/IEC. 33020, Switzerland: ISO/IEC, 2015

[12] D. Galin, "Software quality: Concepts and practice," Chapter: Software Quality Management Standards and Models, B.5 Capability Maturity CMMI Models - Assessment Methodology, pp. 597-602, 2018.

[13] Project management concepts. Process based management. [Online] Available:

https://www.tutorialspoint.com/management_concepts/process_based management.htm

[14] $\bar{A}$. M. E. Hamid, "Application of six sigma methodology in software development," in Proc. 2018 International Conference on Computer, Control, Electrical, and Electronics Engineering (ICCCEEE), pp. 1-5, 2018.

[15] Free online diagram software for making flowcharts. [Online]. Available: https://www.draw.io/

[16] L. Jiuyong, M. Saisai, L. Thuc, L. Lin, and L. Jixue, "Causal decision trees," IEEE Transactions on Knowledge and Data Engineering, pp. 257-271, 2017.

[17] V. Ponomarenko, "The applicability of process-orientation to software development projects," in Proc. International Conference on Information Systems and Management Science (ISMS 2018), 2018, p. 14.

[18] Free calculators and converters. [Online]. Available: https://www.easycalculation.com/statistics/cp-cpk-calculator.php

[19] C. K. Karale, "Process capability and capability index," Internal training session, Gujarat, Alembic Research Center, Presentation, 2017.

Copyright (C) 2020 by the authors. This is an open access article distributed under the Creative Commons Attribution License which permits unrestricted use, distribution, and reproduction in any medium, provided the original work is properly cited (CC BY 4.0).

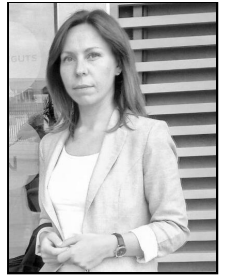

Viktorija Stepanova is a doctoral student at Riga Technical University, Department of Computer Science and Information Technology. She earned her master's from Riga Technical University in the field of business informatics in 2016. As a researcher of the Institute of Applied Computer Science, she was involved in several European and national projects: European Fund Development project "Development of Insurance Distributed Software Based on Intelligent Agents, Modeling and Web Technologies", Latvian Research Council Project in Web Technologies and Artificial Intelligence, Latvian State Research Program in information technologies based on ontologies and models transformation, FP7 project eINTERASIA, etc.

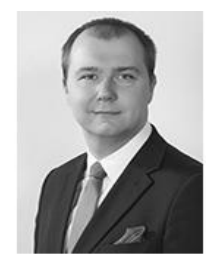

Ingars Erins is the vice-rector for Finance at Riga Technical University and a professor at the Faculty of Computer Science and Information Technology. He has held managerial positions at Riga Technical University at the Faculty of Engineering Economics and Management, as well as in other establishments. He holds Dr.oec. degree from Riga Technical University. $\mathrm{He}$ is the author of numerous publications in the field of finance, banking management and computer science. In 2012, Dr. Oec. Ingars Erins was a member of the Human Capital Development Facilitation working group at the Strategic Analysis Commission, a think tank under the auspices of the President of the Republic of Latvia 